\title{
Pathological fractures of the mandible: A report of ten cases and a review of the literature*
}

\author{
Badreddine Abir ${ }^{\#}$, Alae Guerrouani, Abdeljalil Abouchadi \\ Department of Plastic, Maxillo-Facial Surgery and Stomatology, Mohamed V Military Hospital, Rabat, Morocco \\ Email: "badrdoc@live.fr
}

Received 30 October 2012; revised 15 October 2013; accepted 26 October 2013

Copyright (C 2013 Badreddine Abir et al. This is an open access article distributed under the Creative Commons Attribution License, which permits unrestricted use, distribution, and reproduction in any medium, provided the original work is properly cited.

\begin{abstract}
Introduction: Pathological fractures of the mandible are rare. They account for approximately $2 \%$ of all mandibular fractures. The main purpose of the study is to report our experience concerning this condition and to analyse data and review the literature available. Material and methods: This study reviewed retrospectively the records of patients who presented to the department of Plastic and Maxillofacial surgery between 2000 and 2008 with a pathological fracture of the mandible. The collected data included age, sex, mechanism of injury, aetiology, anatomic site of fracture, treatment and complications. Results: There were 10 patients with an average age of 48 years and 10 months. There were three cases of fracture due to a local malignancy, two cases of osteoradionecrosis, two cases of mandibular cysts, one patient presenting a mandibular histiocytosis, one patient with a metastatic carcinoma (Thyroid), and one case related to mandibular atrophy. Most common mechanisms of injury were chewing and falls. Pathological fractures were often located in the body of the mandible. A surgical approach was performed in most cases. Conclusion: Surgical management of pathological fractures of the mandible depends largely on the aetiology. Complications occur more often because of local condition and bad oral hygiene.
\end{abstract}

Keywords: Mandibular Fracture; Pathological Fracture

\section{INTRODUCTION}

Mandibular fractures are common after high energy facial injury; they represent $36 \%$ to $59 \%$ of all facial fractures [1]. However, pathological fractures of the mandible are uncommon and represent less than $2 \%$ of all

*Conflict of interest: none

${ }^{\#}$ Corresponding author. mandibular fractures [2]. This kind of fracture occurs from a very low energy injury or normally tolerated loading forces in a bone weakened by a pathological condition. Actually, this definition remains controversial, because: a) A low-energy injury is difficult to define and to quantify by scientific means; and b) This definition can't cover all pathological mandibular fractures [3]. Others suggest that pathological fractures occur through a pre-existing lesion or in a diseased part of the bone [4].

This study was realized to determine the aetiology of bony condition that leads to pathological fractures of the mandible seen in our experience, their sites and the treatments we proposed.

\section{MATERIAL AND METHODS}

Between September 2000 and July 2008, 10 patients were treated for pathological fracture of the mandible in our department. Patients' data including: sex, age, mechanism of injury, aetiology, fracture site, treatment and the presence of postoperative complication were analysed and compared with previously published data.

\section{RESULTS (TABLE 1)}

During this period, 317 patients with fractures of the mandible were treated in the department of Plastic and Maxillofacial Surgery. Ten patients were presenting a pathological fracture of the mandible which represents $3,1 \%$ of all mandible fractures seen during the same period. The sex ratio was 6 male/4 female. The average age of the patients was 48.8 with a range of $24-76$ years. The main mechanism of the injury was minimal trauma during mastication (04 cases). Two patients suffered an injury during a fall, two fractures were iatrogenic following dental extraction procedures, and in two cases patients suffered mandible fracture because of a road accident. Regarding aetiology, three patients were diagnosed with direct invasion of the mandible by a primary 
Table 1. Demographic, clinical data, aetiology and treatment referring to the group of examined patients.

\begin{tabular}{cccllll}
\hline Cas & Sexe & Age (yrs) & \multicolumn{1}{c}{ injury } & \multicolumn{1}{c}{ Aetiology } & \multicolumn{1}{c}{ Location } & Treatment \\
\hline 1 & M & 24 & $\begin{array}{l}\text { Surgical remove } \\
\text { of teeth } 36\end{array}$ & Osteoradionecrosis & Mandibular body & Free flap \\
2 & M & 38 & Fall & Metastatic thyroid carcinoma & Mandibular body & Conservative treatment \\
3 & M & 44 & Chewing & Oral squamous cell carcinoma & Symphysis & Free flap \\
4 & F & 42 & Chewing & Osteoradionecrosis & Angle & Free flap \\
5 & F & 57 & Road accident & Periapical cyst & Mandibular body & $\begin{array}{l}\text { Enucleation + Maxillomandibular } \\
\text { fixation }\end{array}$ \\
6 & M & 52 & Fall & Mandibular histiocytosis & Mandibular body & Bone graft \\
7 & F & 65 & Chewing & Oral squamous cell carcinoma & Symphysis & Reconstruction plate \\
8 & M & 76 & Road accident & Mandibular atrophy & Mandibular body & Reconstruction plate \\
9 & M & 45 & Chewing & Oral squamous cell carcinoma & Mandibular body & Free flap \\
10 & F & 45 & $\begin{array}{l}\text { Surgical remove } \\
\text { of teeth 48 }\end{array}$ & Mandible cyst & Angle & $\begin{array}{l}\text { Enucleation + maxillomandibular } \\
\text { fixation }\end{array}$ \\
\hline
\end{tabular}

malignant tumour (Figure 1), two patients were diagnosed with osteoradionecrosis (ORN) of the mandible (Figures 2-4), two patients had mandible cysts (Figure 5), only one patient was presenting a mandibular atrophy (Figure 6), one patient presented a metastatic thyroid carcinoma and one patient was presenting a mandibular histiocytosis. In 8 patients fractures concerned the mandibular body, in the two other cases they occurred in the angle.

Most of the patients were qualified for surgical treatment: Segmental mandibulectomy was realized in 05 patients (02 patients with ORN and 03 patients with local malignancy) and cyst enucleation was performed in two cases. Reconstruction was performed using titanium reconstruction plates in 02 patients (Figure 6), iliac crest bone graft was needed in 01 patient (Figure 7), and free fibula flap was used in 04 patients (Figures 8 and 9). Maxillomandibular fixation was applied for 6 weeks in 02 patients (associated to cyst enucleation). In one patient, the general health status did not permit aggressive procedure and conservative treatment was indicated (liquid diet and antibiotics). Patients with osteoradionecrosis ORN were all sent to hyperbaric oxygen unit for 30 to 40 pre-surgical and post-surgical daily treatment sequences.

Complication rate was $40 \%$ : we have seen exposed plates in 02 patients, surgical site infection in one patient and a late failure of the free fibula flap in one patient.

\section{DISCUSSION}

Pathological fractures involve rarely facial bones. When they occur, they involve almost always the mandible [4]. Most of trauma mandibular fractures involve young male

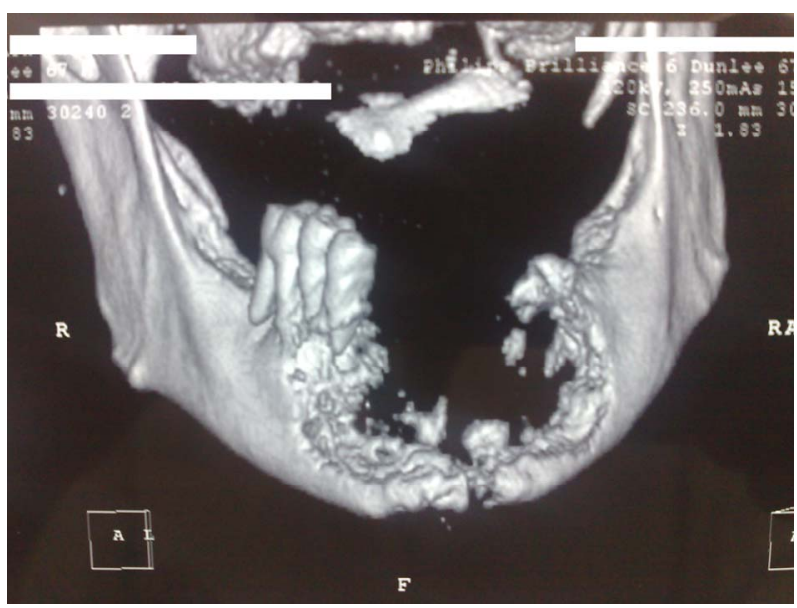

Figure 1. 3D reconstruction of the CT confirmed the presence of fracture of the symphyseal region within the neoplastic infiltration.

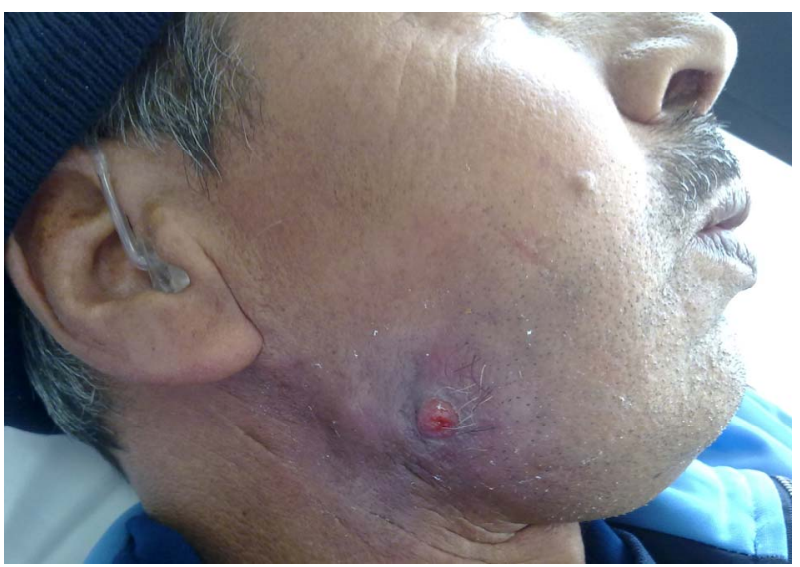

Figure 2. Extraoral view of cutaneous fistula. 

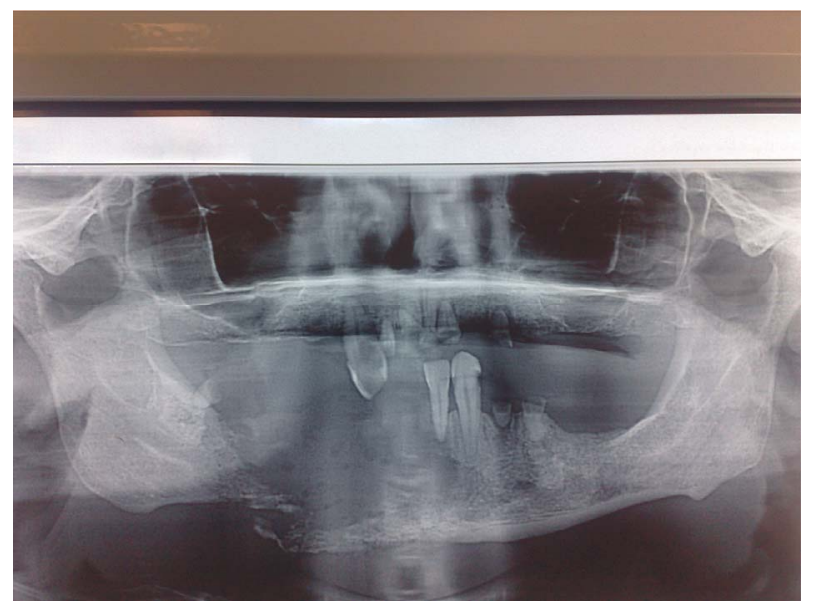

Figure 3. Panoramic radiograph shows pathological fracture in the mandible body. Changes in the bone structure correspond to osteoradionecrosis.

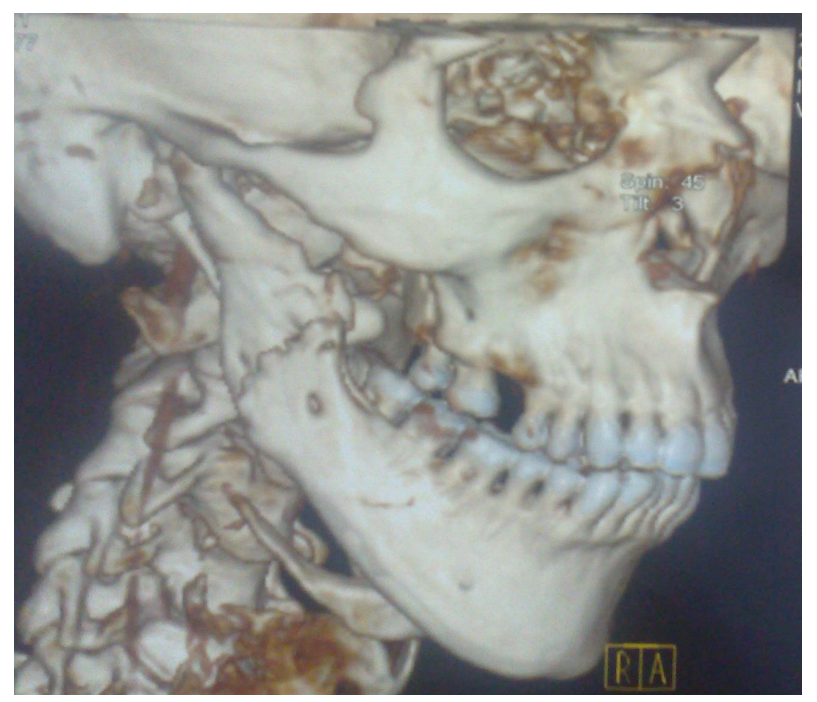

Figure 4. 3D reconstruction of the CT confirmed the presence of a non dislocated fracture in the right body of the mandible.

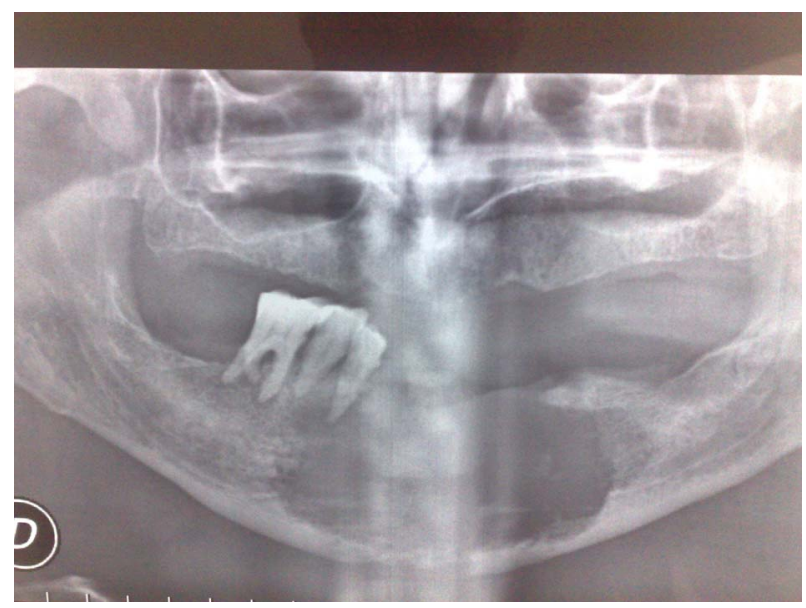

Figure 5. Panoramic radiograph reveals bone destruction in the anterior region of the mandible, due to odontogenic cyst.

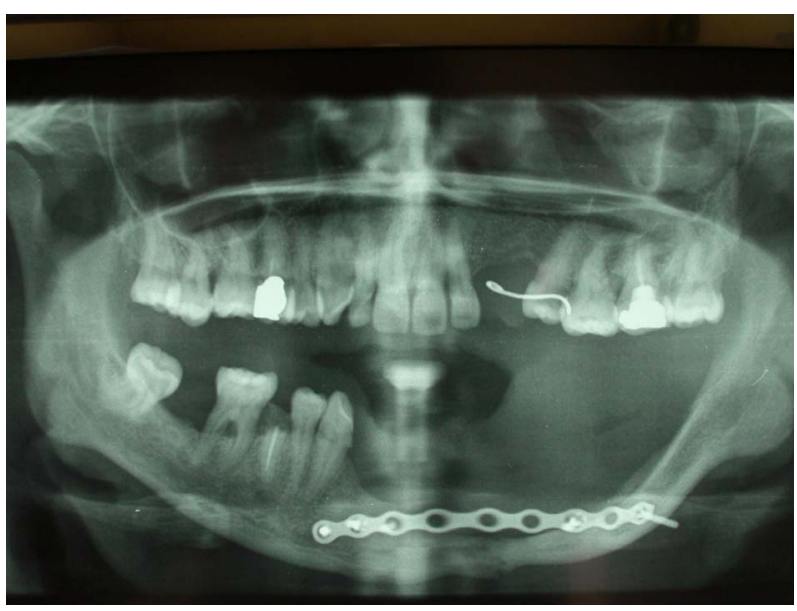

Figure 6. Postoperative radiograph of after reposition and fixation with reconstruction locking plate.

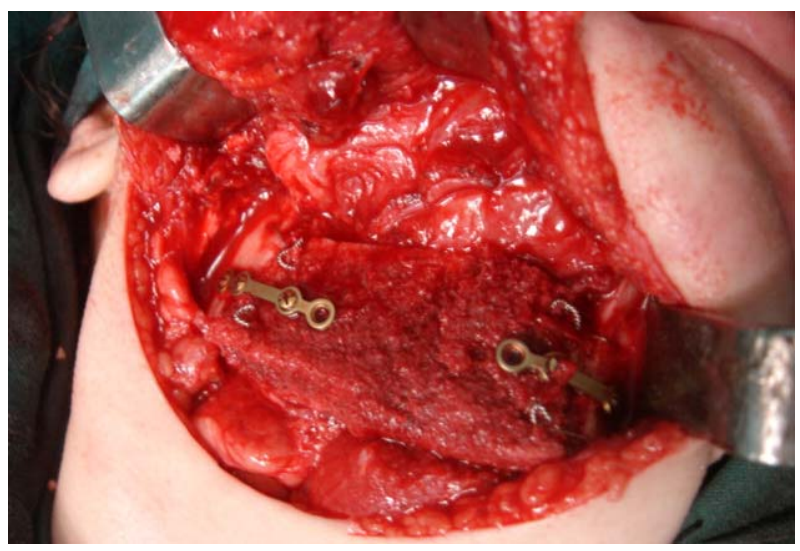

Figure 7. Intraoperative view with mandibular reconstruction by bone graft stabilized with plates.

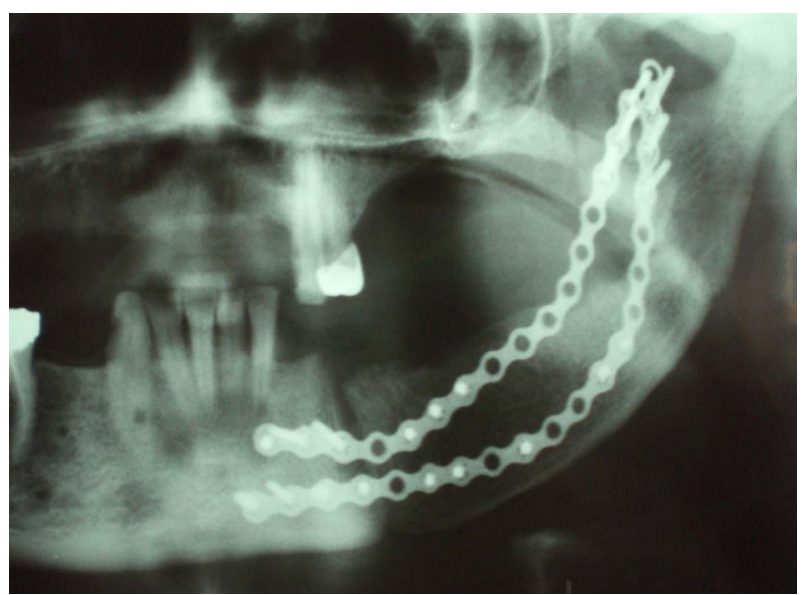

Figure 8. Four months after surgery, the panoramic radiograph reveals a proper integration of the bone graft and a good consolidation of the fracture.

people. In the opposite, pathological fractures occur in old patients. Indeed, our data show an increased rate of pathological mandibular fractures in people over 40 


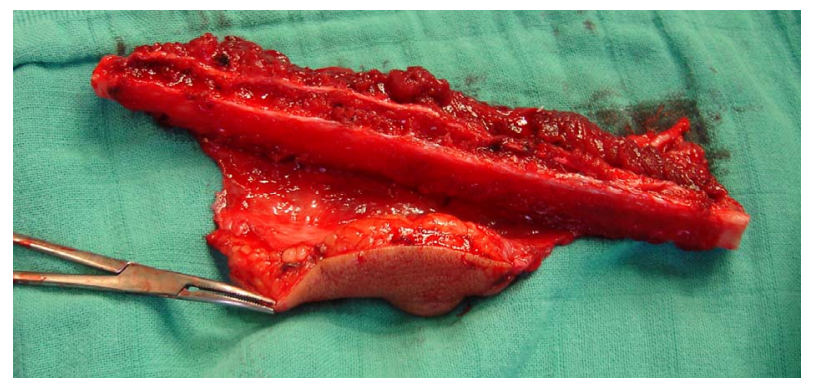

Figure 9. Intraoperative view of a harvested osteocutaneous fibula free flap.

years ( $80 \%$ of our series). This might be explained by the fact that elderly patients are more concerned by malignnant conditions and atrophic edentulous jaws [1]. Copes suggested that spontaneous fractures of the mandible are often in relation with mastication forces. Anterior mandibular fractures are due to the action of depressor mus cles, while posterior fractures are due to the action of elevator muscles [5]. In the most cases, osteoradionecrosis ORN is suggested as a cause of pathological mandibular fractures [2]. ORN occurs after radiotherapy, and is in relation with hypoxia, hypovascularity and hypocellularity as suggested by the 3H theory of Marx [6]. These phenomena alter bone capacity of reparation. They occur more often in angular, retromolar and horizontal parts of mandible because of their unique centromedullar vascularity. A study including 1000 patients who had head and neck radiation showed that 2,6\% of them developed ORN, and $23 \%$ of these progressed to pathological fracture of mandible [7]. In ORN context, pathological fracture of the mandible is classified as a stage III ORN by Marx and Myers [8].

In this study, ORN comes in the second rank after malignancies. Oral primary cancer as spinocellular carcinomas, or mandibular metastasis are also frequently involved in pathological fractures. Leukaemias, lymphomas and especially multiple myeloma are blood productive system cancers that can cause pathological fractures of mandible when they concern this bone. It is estimated that only $1 \%$ of malignant tumours found in the oral region are metastases of breast, prostate, thyroid, kidney or lung cancer [2]. In fact, the true incidence of metastases in mandible is unknown, as radiography exam of this region is not included in systematic survey for metastasis. Facial bones are less often touched by metastases than long bones. It seems like it is because of the decrease of red bone marrow and blood vessels that occurs in the jaws with age. When they occur, metastases concern almost always the mandible. This is thought that it is due to the greater presence of hematopoietic tissue in mandible than in the other facial bones [9].

Osteomyelitis was also described as a frequent cause of pathological mandibular fractures. In a 44 patients study reported by Coletti and Ord [3], osteomyelitis came in second position (19\%) after ORN (49\%). Osteomyelitis can be associated with implants or third moral extractions, and there are often causes underlying predisposing condition such as diabetes.

Biphosphonate related osteonecrosis is a relatively recent recognized pathology, as Marx and other authors (Wang, Migliorati) [10-12] described the first reports of this condition in 2003, even if "phossy jaws" cases were reported more than a century ago. This condition appears often associated with predisposing pathology as corticotherapy or immunosuppressive treatment, chemotherapy, osseous diseases, bad nutritional condition or tobacco consumption and bad oral condition $[11,13]$. The most common clinical presentation is an osteitis occurring after a tooth extraction (86\%) [14]. The physiopathology of osteochemonecrosis remains unclear, however four factors appear to have a role in its occurrence: A) An accumulation of biphosphonates in the jaw, due to a fast osseous turnover in relation to the presence of teeth and the daily activity of jaws. This phenomenon stops bone remodelling around teeth and periodontal ligament. B) A high release of cytokines. C) The inhibition of angiogenesis and the acceleration of apoptosis. D) The immunosuppressive condition seen in all patients with a metastatic disease and under chemotherapy or corticosteroids [15].

Iatrogenic condition as a wisdom-tooth extraction can be the cause of a mandibular fracture. It occurs most frequently in male patients aged between 25 and 50-yearold, in the two weeks following surgery [3]. Fractures in atrophic or long-time edentulous mandible can be seen after a trauma. However, spontaneous fracture in an atrophic mandible is an uncommon event. Luhr et al. [16], defined the atrophic mandible as having less than $20 \mathrm{~mm}$ in its body vertical height. In their study includeing 84 edentulous patients, they classified atrophic mandibles in 3 stages: I) 16 - $20 \mathrm{~mm}$, II) 11 - $15 \mathrm{~mm}$, III) 10 $\mathrm{mm}$ or less. Other conditions can also be involved in pathological fractures of mandible. They can be classified in different ways.

Treatments of pathological fractures of mandible are complex because of their multiple aetiologies, their occurrence in patients suffering several serious diseases, and the local bone condition which is very often infected and non viable. Bone healing in these situations has big chances to fail, and takes longer time. Treatment strategy must be adapted to each patient individually. And even if management strategies are different from aetiology to another, some rules are common according to Coletti and Ord's paper (Figure 10) [3]. A special attention should be paid to optimize the general health condition of the patient. Pain, functional and nutritional problems must be cared, and a soft diet must be started. If a malignant or 


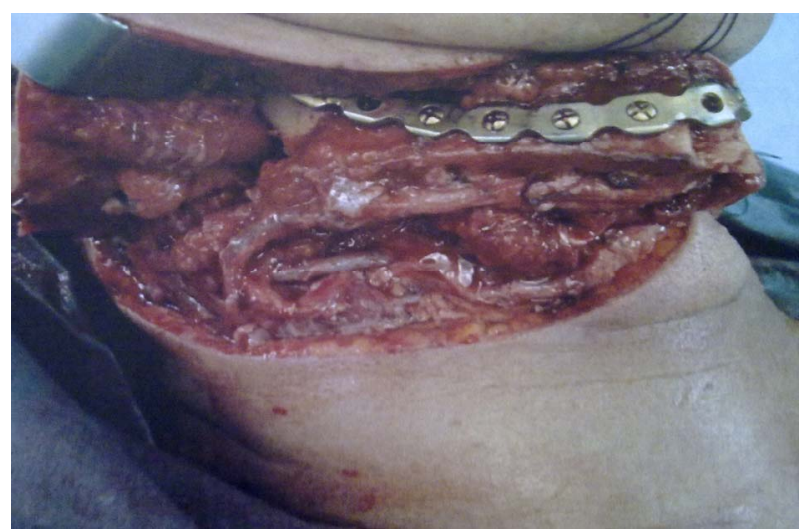

Figure 10. Reconstruction of the mandible with an osteotomized fibula which is affixed to the reconstruction plate.

also a benign disease is present, the treatment of this condition is considered as a priority. In the cases where there is no potential for normal union, bone resection must be performed until arriving to normal bleeding bone. When there is a sufficient normal bone left, traditional reduction is performed and rigid fixation is employed. When a defect is left, the bone continuity is maintained by reconstruction plates. Reconstruction can be performed primarily or secondarily, using reconstructtion plates alone, or associated with bone graft taken from iliac crest for example, or associated with a regional or a micro-vascular composite flap. According to Pogrel et al. [17], non-vascular bone must be only used when the osseous defect is less than $6 \mathrm{~cm}$, in a patient without a history of radiation. It also required an adequate intraoral lining to avoid contact of the bone with the oral cavity.

In the cases of stage III ORN (Marx \& Myers), the surgical treatment consists on a resection of non viable tissues. Magnetic resonance imaging may help to delineate the extent of marrow involvement to assist the surgeon to decide on how much bone requires resection [3]. Another way to determine viable bone is to use tetracycline as proposed by Myers and Marx. Viable bones fixe the tetracycline, which can be revealed by using Wood's light with a wavelength of $365 \mathrm{~nm}$ in the ultraviolet spectrum [8]. Ioannides et al. [18], recommend resection past $1 \mathrm{~cm}$ normal appearing bone, which is recognisable by normal bleeding. If the reconstruction is not done primarily, a long reconstruction plate or less often an external fixation can be used. Non viable soft tissues are excised and soft tissue reparation must be performed primarily. Thirty to forty hyperbaric oxygen HBO treatments must be proposed before surgery. Ten more HBO cures are realised after surgery, after what the disease is classed as a stage IIIR. The reconstruction is now performed secondarily using a bone graft or a composite flap such as a free fibula flap, and ten more HBO cures are proposed. Using antibiotic treatments is not systematic; however, antibiotics must be necessarily used when a surgery is proposed on an irradiated mandible [19]. In anyway, it is important to search a mandibular recurrence of a cancer, or a spinocellular carcinoma grafted on the mandible.

The authors have based their management strategies on their own clinical experience and on the literature data. In cases of malignant or also benign disease, the disease process was addressed as a first priority. In cases of ORN, the bone was excised until normal bleeding was encountered. The continuity defect created was maintained with reconstruction plates and then reconstructed primarily or mostly secondarily. In the few cases where sufficient bone was left (cysts), a traditional fracture reduction and a maxillomandibular fixation were performed.

\section{CONCLUSION}

Pathological fractures are difficult to treat because of their diverse aetiologies and the impact will have relation to normal bone healing. Treatment must take the local and overall condition of the patient into consideration. Free flap reconstruction should be considered when possible, especially in cases secondary to osteoradionecrosis or malignancies.

\section{REFERENCES}

[1] Allan, B.P. and Daly, C.G. (1990) Fractures of the mandible: A 35-year retrospective study. International Journal of Oral and Maxillofacial Surgery, 19, 268-271. http://dx.doi.org/10.1016/S0901-5027(05)80417-5

[2] Gerhards, F., Kuffner, H.D. and Wagner, W. (1998) Pathological fractures of the mandible: A review of the etiology and treatment. International Journal of Oral and Maxillofacial Surgery, 27, 186-190.

http://dx.doi.org/10.1016/S0901-5027(98)80007-6

[3] Coletti, D. and Ord, R.A. (2008) Treatment rationale for pathological fractures of the mandible: A series of 44 fractures. International Journal of Oral and Maxillofacial Surgery, 37, 215-222 http://dx.doi.org/10.1016/j.ijom.2007.09.176

[4] Ezsias, A. and Sugar, A.W. (1994) Pathologic fractures of the mandible: a diagnostic and treatment dilemma. British Journal of Oral and Maxillofacial Surgery, 32, 303-306. http://dx.doi.org/10.1016/0266-4356(94)90051-5

[5] Cope, M.R. (1982) Spontaneous fracture of an atrophic edentulous mandible treated without fixation. British Journal of Oral and Maxillofacial Surgery, 20, 22-30. http://dx.doi.org/10.1016/0007-117X(82)90003-8

[6] Marx, R.E. (1983) Osteoradionecrosis: A new concept of its pathophysiology. Journal of Oral and Maxillofacial Surgery, 41, 283-288.

http://dx.doi.org/10.1016/0278-2391(83)90294-X

[7] Epstein, J.B., Wong, F.L.W. and Stevensom-Moore, P. 
(1987) Osteoradionecrosis: Clinical experience and a proposal for classification. Journal of Oral and Maxillofacial Surgery, 45, 69-71. http://dx.doi.org/10.1016/0278-2391(87)90399-5

[8] Myers, R.A. and Marx, R.E. (1990) Use of hyperbaric oxygen in postradiation head and neck surgery. NCI Monography, 9, 151-157.

[9] Al Gahtani, M., Alqudah, M., Al Shehri, S., et al. (2009) Pathologic fracture of the mandible caused by metastatic follicular thyroid carcinoma. Journal of the Canadian Dental Association, 75, 457-460.

[10] Marx, R.E. (2003) Pamidronate (Aredia) and zoledronate (Zometa) induced avascular necrosis of the jaws: A growing epidemic. Journal of Oral and Maxillofacial Surgery, 61, 1115-1117. http://dx.doi.org/10.1016/S0278-2391(03)00720-1

[11] Wang, J., Goodger, N.M. and Pogrel, M.A. (2003) Osteonecrosis of the jaws associated with chemotherapy. Journal of Oral and Maxillofacial Surgery, 61, 11041107. http://dx.doi.org/10.1016/S0278-2391(03)00328-8

[12] Migliorati, C.A. (2003) Biphosphonates and oral cavity avascular bone necrosis. Journal of Clinical Oncology, 21, 4253-4254. http://dx.doi.org/10.1200/JCO.2003.99.132

[13] Ruggiero, S., Gralow, J., Marx, R.E., Hoff, A.O., Schubert, M.M., Huryn, J.M., et al. (2006) Practical guidelines for the prevention, diagnosis and treatment of osteonecrosis of the jaw in patients with cancer. Journal of Oncology Practice, 2, 7-14. http://dx.doi.org/10.1200/JOP.2.1.7

[14] Rattin, C., Vanoli, A. and Latombe, I. (2008) Extensive osteonecrosis of the jaws associated with biphophonates therapy. Annales d'Otolaryngologie et de Chirurgie Cervico-faciale, 125, 24-29.

http://dx.doi.org/10.1016/j.aorl.2007.09.002

[15] Gering. A., Grange, L., Villier, C., Woeller, A. and Mallaret, M. (2007) Biphosphonates-associated osteonecrosis of the jaw: Review on reported cases. Therapie, 62, 49-54. http://dx.doi.org/10.2515/therapie:2007003

[16] Luhr, H.G., Reidick, T. and Merten, H.A. (1996) Results of treatment of fractures of the atrophic edentulous mandible by compression plating: A retrospective evaluation of 84 consecutive cases. Journal of Oral and Maxillofacial Surgery, 54, 250-254. http://dx.doi.org/10.1016/S0278-2391(96)90733-8

[17] Pogrel, M.A., Podlesh, S., Anthony, J.P. and Alexander, J. (1997) A comparison of vascularised and nonvascularized bone grafts for reconstruction of mandibular continuity defects. Journal of Oral and Maxillofacial Surgery, 55, 1200-1206. http://dx.doi.org/10.1016/S0278-2391(97)90165-8

[18] Ioannides, C., Fossion, E., Boecke, W., Hermans, B. and Jacobs, D. (1994) Surgical management of the osteoradionecrotic mandible with free vascularised composite flaps. Journal of Cranio-Maxillofacial Surgery, 22, 330334. http://dx.doi.org/10.1016/S1010-5182(05)80113-1

[19] Girod, A., Bouletreau, P., Freidel, M. and Breton, P. (2004) Vascularized osseous flaps for mandibular reconstruction after osteoradionecrosis. Revue de Stomatologie et de Chirurgie Maxillo-Faciale, 105, 255-268. http://dx.doi.org/10.1016/S0035-1768(04)72324-4 